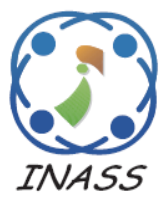

\title{
Groundwater Assessment Using Feature Extraction Algorithm Combined with Complex Proportional Assessment Method and Standard Deviation
}

\author{
Shaaban M. Shaaban ${ }^{1,2 *}$ \\ ${ }^{I}$ Department of Basic Engineering Science, Faculty of Engineering, \\ Menoufia University, Shebin El-Kom, 32511, Egypt. \\ ${ }^{2}$ Department of Electrical Engineering, Faculty of Engineering, \\ Northern Border University, Arar,1321, Saudi Arabia \\ * Corresponding author's Email: shabaan27@gmail.com
}

\begin{abstract}
Groundwater (GW) quality evaluation includes a variety of biological, chemical and physical parameters. The fundamental problem with water quality assessment is the difficulty with which a large number of parameters are evaluated. If all criteria have been used to evaluate the quality of GW, then computational difficulty will certainly increase. In this paper, a new hybrid three-stage assessment approach based on Feature Extraction Algorithm (FEA), standard deviation (SD) and Complex Proportional Assessment Method (COPRAS) was proposed. In the first stage the redundant criteria for GW quality assessment is removed using FEA. Secondly, the weights of the reduct parameters are evaluated based on SD. Finally, GW sites are ranked using (COPRAS). Sixteen GW samples were gathered from several GW wells. The collected samples were investigated for 12 various physicochemical water quality criteria to evaluate GW quality. The results reveal that sulfates (SO4), nitrate (NO3), Fluorides (F), sodium $(\mathrm{Na})$, and Escherichia coli (E. coli) are the main parameters for GW quality assessment. Furthermore, the optimal concentrations of physicochemical parameters: (SO4), (NO3), (F), (Na), and (E. coli) are 18.9(mg/L), 8.18(mg/L), 0.222(mg/L), 21(mg/L), 1.9(MPN/100mL), respectively, with 40 WQI.The suggested approach is compared to three MCDM methods to validate the performance of the proposed methodology. The assessment results gained by the FEA combined with COPRAS and SD significantly minimize computational difficulty, reasonable and accurate. The approach presented in this study improves the system for evaluating GW quality.
\end{abstract}

Keywords: Multi criteria decision making (MCDM), Groundwater (GW), Standard deviation (SD), Complex proportional assessment method (COPRAS).

\section{Introduction}

Water is a vital resource for the property of life on earth. Groundwater (GW) is one of the world's essential water resources, used for basic needs, such as drinking, cooking, industry and agriculture. As a result of the exponential population growth, and the overuse of GW sources, the quality of $\mathrm{GW}$ is continuously deteriorating. In specific, as in amount, GW quality should be considered seriously. A major concern for human life is the quality of water which relates to the physical, biological and chemical characteristics of water, as it is directly related to human health. As the evaluation of water quality is one of the most important issues in GW studies, a number of methods for evaluating quality of the water have been constructed. One of the old approaches is the Schuler map; this approach includes an evaluation of drinking water in relation to chemical parameters separately and at an aquifer level [1]. Geographical information system (GIS) was used in the study area to analyze the spatial distribution of the groundwater quality index [2]. The World Health Organization (WHO) guidelines for a range of drinking water indices have been established [3]. Multi-Criteria Decision-Making (MCDM) methods are considered to be effective techniques in diverse areas, such as; contractors assessment, projects management, products selection, construction of roads, etc. 
TOPSIS (Technique for Order Preference by Similarity Ideal Solution) was used as supplier selection method [4].For mobile services evaluation, the VIKOR methodology (Vlsekriterijumska Optimizaciya I Kompromisno Resenje) was applied [5]. Multi-Objective Optimization by Ratio Analysis (MOORA) approach was used to determine and maximize the influence of the identified process factors [6]. EDAS has been used successfully to determine the optimal set of operating parameters of a diesel engine [7]. In [8] the Fuzzy-AHP weighted is carried out with Fuzzy ordered Average (FOWA) for groundwater quality index development. Another method based on Fuzzy comprehensive evaluation has been proposed in [9] for GW assessment. A methodology was developed for the ranking of water quality using the Order of Preference Technique Similar to Ideal Solution (TOPSIS) and the Entropy Weight Method [10]. In [11], to establish numerous water quality indices (WQI) and a method for grading groundwater wells, Fuzzy VIKOR dependent water quality evaluation methodology was suggested. COPRAS is an MCDM tool utilized by multiple researchers to solve several different problems. The benefits of COPRAS methodology are; COPRAS approach is very simple to implement, as it needs much less computation than other techniques and the principal advantage of COPRAS relative to other MCDM methods is to be able to compute degree of utility [12]. Weight determination is a critical feature of water quality management, since the weights of the criteria will certainly affect the evaluation results. Thus, enhanced information has been provided about how to select an effective form of determination. A wide range of techniques of weight parameters evaluation are used to compute the quality of the water [13-14]. Standard deviation weight methodology is used in this study to evaluate the weights of the water assessment factors despite its simplicity and accessibility. In addition to weight determination, parameter selection seems to be another critical problem when determining quality of the water. During water quality investigation, a wide number of factors are gathered, but not all criteria are significant with the same degree, and some factors are also insignificant to the results of the evaluation. When all factors that collected are added to determine water quality, it would certainly be difficult to evaluate. It is common to select criteria dependent on individual expertise to decrease the parameters of information system, but this is impractical and to some degree inefficient. Different methods to reduce dimensions of input spaces are available, such as Principal Component Analysis (PCA) [15] and Factor Analysis (FA) [16]. In this paper, FEA combined with COPRAS and SD is proposed to select the most appropriate GW well among the feasible alternatives. FEA is used to execute variable reduction before water quality evaluation, $\mathrm{SD}$ is applied to calculate the weights of variables, and COPRAS is applied to evaluate water quality. The advantage of the suggested approach is not only in improving support to the decision-making process in selecting the best alternative but also in dealing with datasets with a large number of input variables, FEA can obviously minimize the parameters of input space and calculation difficulty. A considerable amount of time is saved at the same time. The rest of this paper is structured as follows. FEA method with its calculation steps, COPRAS with its computation steps and SD are presented in Section 2. The methodology of the suggested approach is given in section 3. The implementation of the proposed approach is validated with the best GW well selection problem in section 4. Lastly, in section 5 the conclusions are discussed.

\section{Methods}

\subsection{Feature extraction algorithm}

Some information is necessary in an information system for analysis of the system characteristics, but some information is unnecessary. Feature extraction algorithm (FEA) can be used to eliminate the redundant data while preserving the quality of sorting of the current circumstances. The features extracted are the reduct. For an information system $S=$ $(U, A, V, f)$, where $U$ is a finite nonempty set of objects and $A$ is a finite nonempty set of attributes, $V$ is a nonempty set of values, and $f$ is an information function that maps an object in $U$ to exactly one value in $V$, the feature reduction steps is given as follows[17]:

Step1: Evaluate the value $S_{a}^{d}$ which used as a measure to rank attributes and subsequently select the best attribute for superset of reduct by:

$$
\begin{aligned}
& S^{d}=n^{2}-\sum_{i=1}^{m}\left(n^{i}\right)^{2} \\
& S P_{a}^{d}=\sum_{P=1}^{k}\left(\left(n_{p}\right)^{2}-\sum_{i=1}^{m}\left(n_{p}^{i}\right)^{2}\right) \\
& S_{a}^{d}=\frac{1}{2}\left(S^{d}-S P_{a}^{d}\right)
\end{aligned}
$$

Where, $n^{i}$ is the number of cases in decision class $i$, $n_{p}$ is the number of cases that has symbolic value $p$ for criteria a, and $\mathrm{n}_{\mathrm{p}}^{\mathrm{i}}$ is the number of cases from decision class $i$ that has symbolic value $p$ for criteria a. 
Step2: Select the attribute with the maximum $S_{a}^{d}$ Step3: Subsequently use the selected attribute to partition the decision table into equivalence classes.

Step4: Repeat the steps from step 1 to step 3 with each equivalence class

Step5: Select the attribute with the maximum $\sum S_{a}^{d}$

Step6: Repeat the steps from step 1 to step 5 till $\sum S_{a}^{d}=0$ for all attributes.

\subsection{Standard deviation.}

The standard deviation $(S D)$ is considered as measurement for the weights of the different criteria. The weights of the attributes using $(S D)$ are determined by the following steps:

Step1: Create the decision matrix of, $X$

$$
X=\left[X_{i j}\right]_{m n}\left[\begin{array}{lccc}
x_{11} & x_{12} & \ldots & x_{1 n} \\
x_{21} x_{22} & \ldots & x_{2 n} \\
\vdots & \vdots & \ddots & \vdots \\
x_{m 1} x_{m 2} & \ldots & x_{m n}
\end{array}\right]
$$

Where $X_{i j}$ is the performance value of ith alternative on jth criterion, $n$ is the number of parameters and $m$ is the number of alternatives.

Step2: Normalize the decision matrix to obtain dimensionless values from various criteria using the following formula:

$$
X_{i j}^{S}=\frac{X_{i j}-\min X_{i j}}{\max X_{i j}-\min X_{i j}}
$$

Step3: Evaluation of the (SD) for every criterion using the following formula:

$$
S D_{j}=\sqrt{\frac{1}{m} \sum_{i=1}^{m}\left(X_{i j}^{S}-\bar{X}_{j}\right)^{2}}
$$

where $X_{i j}$ is the mean of the values of the jth Criteria after normalization and $\mathrm{j}=, 2,3, \ldots, \mathrm{n}$.

Step4: Finally, the weight foe each criterion is computed the following equation:

$$
W_{J}=\frac{S D_{j}}{\sum_{j=1}^{n} S D_{j}}
$$

\subsection{Complex proportional assessment (COPRAS)}

Zavadskas et al. developed the method of preference ranking for complex proportional assessment (COPRAS) [18]. This approach considers separate the effect of maximization and minimization parameters on the results of the evaluation. The performance of the alternatives in terms of different criteria and the corresponding criteria weights is taken into account. This approach chooses the best decision, taking into account the optimal and worst solutions. The COPRAS technique was applied in different fields such as material selection, management, construction, economics, etc. [19-22]. The COPRAS technique steps are defined as follows [23]:

Step1: determine the main criteria and define the alternatives.

Step2: Create the decision matrix of, $\mathrm{X}$

$$
X=\left[X_{i j}\right]_{m n}=\left[\begin{array}{cccc}
x_{11} x_{12} & \ldots & x_{1 n} \\
x_{21} x_{22} \ldots & x_{2 n} \\
\vdots & \vdots & \ddots & \vdots \\
x_{m 1} x_{m 2} & \ldots & x_{m n}
\end{array}\right]
$$

Where $X_{i j}$ is the performance value of $i^{\text {th }}$ alternative on $j^{\text {th }}$ criterion, $n$ is the number of parameters and $m$ is the number of alternatives.

Step3: Normalize the decision matrix to obtain dimensionless values from various criteria using the following formula, $R$.

$$
R=\left[r_{i j}\right]_{m n}=\frac{x_{i j}}{\sum_{i=1}^{m} x_{i j}}
$$

Step4: Calculate the weighted normalized decision matrix, $D$.

$$
D=\left[y_{i j}\right]_{m n}=r_{i j} \times w_{j(i=1,2, \ldots, m ; j=1,2, \ldots, n)}
$$

Step5: The sums weighted standardized values are determined using the following formulas for beneficial as well as non-beneficial parameters:

$$
\begin{aligned}
S_{+i} & =\sum_{j=1}^{n} y_{+i j} \\
S_{-i} & =\sum_{j=1}^{n} y_{-i j}
\end{aligned}
$$

Where $y_{+i j}$ and $y_{-i j}$ are the weighted normalized values for the beneficial and non-beneficial attributes, respectively.

Step 6: Calculation the relative importance of each alternative, $Q i$ :

$$
Q_{i}=S_{i}+\frac{S_{-\min } \cdot \sum_{i=1}^{m} S_{-i}}{S_{-i} \cdot \sum_{i=1}^{m}\left(S_{-\min } / S_{-i}\right)}, i=1,2,3, \ldots m
$$

Where $S_{-\min }$ is the minimum value of $S_{i}$.

Step 7: Evaluation of the quantitative utility, $U_{i}$

$$
U_{i}=\frac{Q_{i}}{Q_{\max }} \cdot 100 \%
$$

Here, $Q_{\max }$ is the maximum relative importance value. The utility values of the determined 


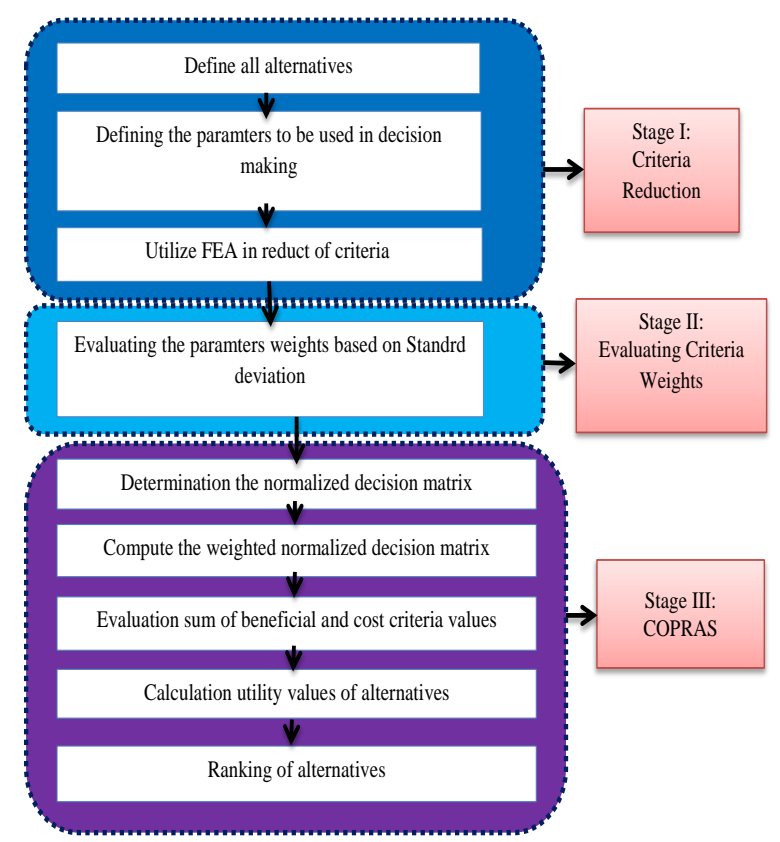

Figure. 1 The schematic structure of the proposed approach

alternatives are between 0 and $100 \%$. Finally, the most desirable alternative is the maximum utility factor.

\section{Proposed methodology}

The technique offered is composed of three elementary stages:

$1^{\text {st }}$ Stage. Reduction of criteria using FEA algorithm $2^{\text {nd }}$ Stage. Weight computation of reduct parameters using standard deviation method

$3^{\text {rd }}$ Stage. Alternatives ranking by using of complex proportional assessment (COPRAS).
The schematic structure of the proposed approach is shown in Fig. 1.

\section{Results, validations and discussions}

In this section, a practical application is given to validate the performance and the efficiency of the suggested approach for groundwater quality assessment.

\subsection{Information system of evaluating groundwater quality}

Groundwater quality evaluation problem includes a variety of chemical and physical parameters. Sixteen GW samples were gathered from several GW wells in Jordan [24] as shown in Table 1. For each sample, twelve parameter including hydrogen ion concentration (pH-a1), total dissolved solids (TDS(mg/L)-a2), total hardness (TH(mg/L)-a3), Turbidity (Turb(NTU)-a4), sulfates (SO4(mg/L)-a5), chlorides ( $\mathrm{Cl}(\mathrm{mg} / \mathrm{L})-\mathrm{a} 6)$, nitrate (NO3(mg/L)-a7), Fluorides $(\mathrm{F}(\mathrm{mg} / \mathrm{L})-\mathrm{a} 8)$, sodium $(\mathrm{Na}(\mathrm{mg} / \mathrm{L})-\mathrm{a} 9)$, Zinc $(\mathrm{Zn}(\mathrm{mg} / \mathrm{L})-\mathrm{a} 10), \quad$ iron $(\mathrm{Fe}(\mathrm{mg} / \mathrm{L})-\mathrm{a} 11), \quad$ and Escherichia coli (E. coli(MPN/100mL)-a12) were investigated. These parameters are taken as condition attributes in our approach. In the other hand the water quality index (WQI) is indicated as decision attribute for each sample.

\subsection{Discretization and coding of information system}

The information system is discretized by transforming the continuous values of the quantitative parameters (a1-a12), and the degision

Table 1. Groundwater samples information system

\begin{tabular}{|c|c|c|c|c|c|c|c|c|c|c|c|c|c|}
\hline \multirow{2}{*}{$\begin{array}{c}\text { W. } \\
\text { NO. }\end{array}$} & \multicolumn{1}{|c|}{ a1 } & a2 & a3 & a4 & a5 & a6 & a7 & a8 & a9 & a10 & a11 & a12 & Decision \\
\cline { 2 - 17 } & pH & TDS & TH & Turb & SO4 & Cl & NO3 & F & Na & Zn & Fe & E.coli & WQI \\
\hline w1 & 7.15 & 446 & 424 & 0.3 & 28 & 53 & 45 & 0.229 & 25 & 0.1 & 0.04 & 33 & 274 \\
\hline w2 & 7.43 & 424 & 376 & 0.1 & 35 & 70 & 61 & 0.364 & 41 & 0.016 & 0.04 & 34 & 287 \\
\hline w3 & 7.4 & 671 & 470 & 0.2 & 53 & 160 & 33 & 0.486 & 99 & 0.016 & 0.04 & 9.4 & 113 \\
\hline w4 & 7.81 & 429 & 263 & 0.45 & 36 & 68 & 46 & 0.411 & 30 & 0.03 & 0.04 & 3.7 & 66 \\
\hline w5 & 7.29 & 454 & 407 & 0.7 & 32 & 83 & 36 & 0.304 & 36 & 0.016 & 0.04 & 590 & 4295 \\
\hline w6 & 7.4 & 438 & 308 & 0.55 & 35 & 74 & 38 & 0.338 & 32 & 0.03 & 0.04 & 6.4 & 83 \\
\hline w7 & 7.84 & 329 & 218 & 0.08 & 9 & 24 & 22 & 0.306 & 14 & 0.016 & 0.04 & 1.8 & 44 \\
\hline w8 & 7.78 & 464 & 236 & 0.4 & 37 & 134 & 2.3 & 0.709 & 94 & 0.016 & 0.09 & 1.8 & 52 \\
\hline w9 & 7.48 & 424 & 290 & 0.25 & 60 & 115 & 1 & 1.9 & 52 & 0.016 & 0.04 & 1.8 & 55 \\
\hline w10 & 8.71 & 262 & 23 & 0.45 & 42 & 47 & 7.3 & 0.124 & 80 & 0.016 & 0.1 & 1.8 & 46 \\
\hline w11 & 7.96 & 680 & 283 & 0.23 & 37 & 249 & 22 & 0.332 & 112 & 0.016 & 0.04 & 1.8 & 60 \\
\hline w12 & 7.28 & 1417 & 861 & 4.8 & 605 & 187 & 1 & 1.523 & 145 & 0.06 & 0.11 & 1.8 & 96 \\
\hline w13 & 7.24 & 565 & 506 & 0.1 & 67 & 132 & 16 & 0.341 & 73 & 0.016 & 0.04 & 1.9 & 54 \\
\hline w14 & 7.82 & 391 & 289 & 0.1 & 16 & 59 & 17 & 0.256 & 20 & 0.016 & 0.04 & 3.7 & 59 \\
\hline w15 & 7.63 & 337 & 267 & 0.75 & 39 & 54 & 1.9 & 0.901 & 23 & 0.016 & 0.04 & 6.4 & 80 \\
\hline w16 & 7.61 & 194 & 118 & 0.05 & 18.9 & 37 & 8.18 & 0.222 & 21 & 0.016 & 0.04 & 1.9 & 40 \\
\hline
\end{tabular}


Table 2. Definition of attribute coding

\begin{tabular}{|c|c|c|c|c|c|c|}
\hline \multirow{2}{*}{ Attributes } & \multicolumn{5}{|c|}{ Code } \\
\cline { 3 - 7 } & & I & II & III & IV & V \\
\hline a1 & pH & $\mathrm{a} 1 \leq 6.5$ & $6.5<\mathrm{a} 1 \leq 7$ & $7<\mathrm{a} 1 \leq 7.5$ & $7.5<\mathrm{a} 1 \leq 8.5$ & $\mathrm{a} 1>8.5$ \\
\hline $\mathrm{a} 2$ & $\mathrm{TDS}$ & $\mathrm{a} 2 \leq 300$ & $300<\mathrm{a} 2 \leq 500$ & $500<\mathrm{a} 2 \leq 1000$ & $1000<\mathrm{a} 2 \leq 2000$ & $\mathrm{a} 2>2000$ \\
\hline $\mathrm{a} 3$ & $\mathrm{TH}$ & $\mathrm{a} 3 \leq 150$ & $150<\mathrm{a} 3 \leq 300$ & $300<\mathrm{a} 3 \leq 450$ & $450<\mathrm{a} 3 \leq 550$ & $\mathrm{a} 3>550$ \\
\hline $\mathrm{a} 4$ & Turb & $\mathrm{a} 1 \leq 0.05$ & $0.05<\mathrm{a} 1 \leq 1$ & $1<\mathrm{a} 1 \leq 5$ & $5<\mathrm{a} 1 \leq 10$ & $\mathrm{a} 1>10$ \\
\hline $\mathrm{a} 5$ & $\mathrm{SO} 4$ & $\mathrm{a} 5 \leq 50$ & $50<\mathrm{a} 5 \leq 150$ & $150<\mathrm{a} 5 \leq 250$ & $250<\mathrm{a} 5 \leq 350$ & $\mathrm{a} 5>350$ \\
\hline $\mathrm{a} 6$ & $\mathrm{Cl}$ & $\mathrm{a} 6 \leq 50$ & $50<\mathrm{a} 6 \leq 150$ & $150<\mathrm{a} 6 \leq 250$ & $250<\mathrm{a} 6 \leq 350$ & $\mathrm{a} 6>350$ \\
\hline $\mathrm{a} 7$ & $\mathrm{NO} 3$ & $\mathrm{a} 7 \leq 2$ & $2<\mathrm{a} 7 \leq 5$ & $5<\mathrm{a} 7 \leq 20$ & $20<\mathrm{a} 7 \leq 30$ & $\mathrm{a} 7>30$ \\
\hline $\mathrm{a} 8$ & $\mathrm{~F}$ & $\mathrm{a} 8 \leq 0.5$ & $0.5<\mathrm{a} 8 \leq 1$ & $1<\mathrm{a} 8 \leq 1.5$ & $1.5<\mathrm{a} 8 \leq 2$ & $\mathrm{a} 8>2$ \\
\hline $\mathrm{a} 9$ & $\mathrm{Na}$ & $\mathrm{a} 9 \leq 100$ & $100<\mathrm{a} 9 \leq 200$ & $200<\mathrm{a} 9 \leq 250$ & $250<\mathrm{a} 9 \leq 300$ & $\mathrm{a} 9>300$ \\
\hline $\mathrm{a} 10$ & Zn & $\mathrm{a} 10 \leq .05$ & $0.05<\mathrm{a} 10 \leq 0.5$ & $0.5<\mathrm{a} 10 \leq 1$ & $1<\mathrm{a} 10 \leq 5$ & $\mathrm{a} 10>5$ \\
\hline $\mathrm{a} 11$ & $\mathrm{Fe}$ & $\mathrm{a} 11 \leq 0.1$ & $0.1<\mathrm{a} 11 \leq 0.2$ & $0.2<\mathrm{a} 11 \leq 0.3$ & $0.3<\mathrm{a} 11 \leq 1.5$ & $\mathrm{a} 11>1.5$ \\
\hline $\mathrm{a} 12$ & $\mathrm{E} . \mathrm{coli}$ & $\mathrm{a} 1 \leq 1.1$ & $1.1<\mathrm{a} 1 \leq 2.2$ & $2.2<\mathrm{a} 1 \leq 10$ & $10<\mathrm{a} 1 \leq 50$ & $\mathrm{a} 1>50$ \\
\hline $\mathrm{D}$ & $\mathrm{WQI}$ & $\mathrm{D} \leq 50$ & $50<\mathrm{D} \leq 100$ & $100<\mathrm{D} \leq 200$ & $200<\mathrm{D} \leq 300$ & $\mathrm{D}>300$ \\
\hline
\end{tabular}

Table 3. Coded information system

\begin{tabular}{|c|c|c|c|c|c|c|c|c|c|c|c|c|c|}
\hline \multirow{3}{*}{$\begin{array}{l}\text { W. } \\
\text { NO. }\end{array}$} & \multicolumn{12}{|c|}{ Condition parameter } & \multirow{2}{*}{$\frac{\text { Decision }}{\mathrm{D}}$} \\
\hline & a1 & $\mathrm{a} 2$ & a3 & $\mathrm{a} 4$ & a5 & $\mathrm{a} 6$ & a7 & a8 & a9 & a10 & a11 & a12 & \\
\hline & $\mathrm{pH}$ & TDS & $\mathrm{TH}$ & Turb & $\mathrm{SO} 4$ & $\mathrm{Cl}$ & NO3 & $\mathrm{F}$ & $\mathrm{Na}$ & $\mathrm{Zn}$ & $\mathrm{Fe}$ & E.coli & WQI \\
\hline w1 & II & II & III & II & I & II & $\mathrm{V}$ & $\mathrm{I}$ & $\mathrm{I}$ & II & $\mathrm{I}$ & IV & IV \\
\hline w2 & II & II & III & II & $\mathrm{I}$ & II & $\mathrm{V}$ & $\mathrm{I}$ & $\mathrm{I}$ & $\mathrm{I}$ & $\mathrm{I}$ & IV & IV \\
\hline w3 & II & III & IV & II & II & III & $\mathrm{V}$ & $\mathrm{I}$ & $\mathrm{I}$ & $\mathrm{I}$ & $\mathrm{I}$ & III & III \\
\hline w4 & III & II & II & II & I & II & $\mathrm{V}$ & I & I & $\mathrm{I}$ & I & III & II \\
\hline w5 & II & II & III & II & I & II & $\mathrm{V}$ & I & I & $\mathrm{I}$ & I & $\mathrm{V}$ & $\mathrm{V}$ \\
\hline w6 & II & II & III & II & I & II & $\mathrm{V}$ & I & I & $\mathrm{I}$ & I & III & II \\
\hline w7 & III & II & II & II & I & I & IV & I & I & I & I & II & I \\
\hline w8 & III & II & II & II & I & II & II & II & $\mathrm{I}$ & $\mathrm{I}$ & $\mathrm{I}$ & II & II \\
\hline w9 & II & II & II & II & II & II & $\mathrm{I}$ & IV & I & $\mathrm{I}$ & $\mathrm{I}$ & II & II \\
\hline w10 & $\mathrm{V}$ & $\mathrm{I}$ & $\mathrm{I}$ & II & $\mathrm{I}$ & $\mathrm{I}$ & III & I & $\mathrm{I}$ & $\mathrm{I}$ & II & II & $\mathrm{I}$ \\
\hline w11 & III & III & II & II & $\mathrm{I}$ & III & IV & $\mathrm{I}$ & II & $\mathrm{I}$ & $\mathrm{I}$ & II & II \\
\hline w12 & II & IV & $\mathrm{V}$ & III & $\mathrm{V}$ & III & $\mathrm{I}$ & IV & II & II & II & II & II \\
\hline w13 & II & III & IV & II & II & II & III & $\mathrm{I}$ & $\mathrm{I}$ & $\mathrm{I}$ & $\mathrm{I}$ & II & II \\
\hline w14 & III & II & II & II & $\mathrm{I}$ & II & III & $\mathrm{I}$ & I & $\mathrm{I}$ & I & III & II \\
\hline w15 & III & II & II & II & I & II & I & II & I & I & I & III & II \\
\hline w16 & III & I & I & II & I & I & III & I & I & I & I & II & I \\
\hline
\end{tabular}

attribute (D) into qualitative terms. The condition attributes of chemical and physical parameters for groundwater samples are coded into five qualitative terms; (I, II, III, IV, and V). Furthermore, the decision attribute (D) is coded into five qualitative terms; (I (excellent), II (good), III (moderate), IV (poor), and $\mathrm{V}$ (very poor)). The definition of attribute coding is shown in Table 2. This coding method is applied as presented in the coded information system of Table 3.

\subsection{Groundwater Information system reduction}

In this step Feature Extraction Algorithm (FEA) is applied for the coded information system in table III for extracting the reduct. The reduction result obtained as the output of the (FEA) can be written as $\left\{a_{5}, a_{7}, a_{8}, a_{9}, a_{12}\right\}$. According to the FEA algorithm result the parameters $\left\{a_{1}, a_{2}, a_{3}, a_{4}, a_{6}, a_{10}, a_{11}\right\}$ can be omitted from Table 1 and the reduct Table 4 is obtained.

\subsection{Calculation the weights of the assessment parameters by standard deviation}

The weights of parameters for GW assessment are determined using the standard deviation. To evaluate the standard deviation, standardization of the range was performed using Eq. (3) to turn different scales and units into specific observable units between different $\mathrm{GW}$ assessment parameters to measure their weights. The standard deviation (SD) is then calculated for every assessment parameter using Eq. (4). The next step after determining the standard deviation for all assessment parameters is to 
Table 4. Information system reduct

\begin{tabular}{|c|c|c|c|c|c|c|}
\hline \multirow{2}{*}{$\begin{array}{c}\text { W. } \\
\text { NO. }\end{array}$} & \multicolumn{5}{|c|}{ Condition parameter } & Decision \\
\cline { 2 - 7 } & a5 & a7 & a8 & a9 & a12 & D \\
\hline w1 & 28 & 45 & 0.229 & 25 & 33 & 274 \\
\hline w2 & 35 & 61 & 0.364 & 41 & 34 & 287 \\
\hline w3 & 53 & 33 & 0.486 & 99 & 9.4 & 113 \\
\hline w4 & 36 & 46 & 0.411 & 30 & 3.7 & 66 \\
\hline w5 & 32 & 36 & 0.304 & 36 & 590 & 4295 \\
\hline w6 & 35 & 38 & 0.338 & 32 & 6.4 & 83 \\
\hline w7 & 9 & 22 & 0.306 & 14 & 1.8 & 44 \\
\hline w8 & 37 & 2.3 & 0.709 & 94 & 1.8 & 52 \\
\hline w9 & 60 & 1 & 1.9 & 52 & 1.8 & 55 \\
\hline w10 & 42 & 7.3 & 0.124 & 80 & 1.8 & 46 \\
\hline w11 & 37 & 22 & 0.332 & 112 & 1.8 & 60 \\
\hline w12 & 605 & 1 & 1.523 & 145 & 1.8 & 96 \\
\hline w13 & 67 & 16 & 0.341 & 73 & 1.9 & 54 \\
\hline w14 & 16 & 17 & 0.256 & 20 & 3.7 & 59 \\
\hline w15 & 39 & 1.9 & 0.901 & 23 & 6.4 & 80 \\
\hline w16 & 18.9 & 8.18 & 0.222 & 21 & 1.9 & 40 \\
\hline
\end{tabular}

Table 5. Weights of the GW assessment parameters.

\begin{tabular}{|c|c|c|c|c|c|}
\hline \multirow{2}{*}{$\begin{array}{c}\text { W. } \\
\text { NO. }\end{array}$} & \multicolumn{4}{|c|}{ Standardized mean of conditional parameters } \\
\cline { 2 - 6 } & $\mathrm{a} 5$ & $\mathrm{a} 7$ & $\mathrm{a} 8$ & $\mathrm{a} 9$ & $\mathrm{a} 12$ \\
\hline & SO4 & NO3 & $\mathrm{F}$ & $\mathrm{Na}$ & E.coli \\
\hline w1 & 0.0319 & 0.7333 & 0.0591 & 0.0840 & 0.0530 \\
\hline w2 & 0.0436 & 1 & 0.1351 & 0.2061 & 0.0547 \\
\hline w3 & 0.0738 & 0.5333 & 0.2038 & 0.6489 & 0.0129 \\
\hline w4 & 0.0453 & 0.7500 & 0.1616 & 0.1221 & 0.0032 \\
\hline w5 & 0.0386 & 0.5833 & 0.1014 & 0.1679 & 1 \\
\hline w6 & 0.0436 & 0.6167 & 0.1205 & 0.1374 & 0.0078 \\
\hline w7 & 0 & 0.3500 & 0.1025 & 0 & 0 \\
\hline w8 & 0.0470 & 0.0217 & 0.3294 & 0.6107 & 0 \\
\hline w9 & 0.0856 & 0 & 1 & 0.2901 & 0 \\
\hline w10 & 0.0554 & 0.1050 & 0 & 0.5038 & 0 \\
\hline w11 & 0.0470 & 0.3500 & 0.1171 & 0.7481 & 0 \\
\hline w12 & 1 & 0.0000 & 0.7877 & 1 & 0 \\
\hline w13 & 0.0973 & 0.2500 & 0.1222 & 0.4504 & 0.0002 \\
\hline w14 & 0.0117 & 0.2667 & 0.0743 & 0.0458 & 0.0032 \\
\hline w15 & 0.0503 & 0.0150 & 0.4375 & 0.0687 & 0.0078 \\
\hline w16 & 0.0166 & 0.1197 & 0.0552 & 0.0534 & 0.0002 \\
\hline SD & 0.2322 & 0.3045 & 0.2711 & 0.2922 & 0.2404 \\
\hline W $_{j}$ ) & 0.17326 & 0.22714 & 0.20228 & 0.21799 & 0.17933 \\
\hline & & & & & \\
\hline
\end{tabular}

evaluate their $W_{j}$ weights, with Eq. (5). The normalized values and the corresponding weights of the assessment parameters are indicated in Table 5.

\subsection{Assessment the available locations of groundwater wells by COPRAS}

In COPRAS method, firstly the parameters for groundwater assessment are transformed into dimensionless values using linear normalization procedure, so that all these parameters can be
Table 6. Weighted normalized decision matrix

\begin{tabular}{|c|c|c|c|c|c|}
\hline W. & $\mathrm{a} 5$ & $\mathrm{a} 7$ & $\mathrm{a} 8$ & $\mathrm{a} 9$ & $\mathrm{a} 12$ \\
\cline { 2 - 6 } NO. & SO4 & NO3 & $\mathrm{F}$ & $\mathrm{Na}$ & E.coli \\
\hline w1 & 0.0042 & 0.0286 & 0.0053 & 0.0061 & 0.0084 \\
\hline w2 & 0.0053 & 0.0387 & 0.0084 & 0.0100 & 0.0087 \\
\hline w3 & 0.0080 & 0.0210 & 0.0112 & 0.0241 & 0.0024 \\
\hline w4 & 0.0054 & 0.0292 & 0.0095 & 0.0073 & 0.0009 \\
\hline w5 & 0.0048 & 0.0229 & 0.0070 & 0.0087 & 0.1509 \\
\hline w6 & 0.0053 & 0.0241 & 0.0078 & 0.0078 & 0.0016 \\
\hline w7 & 0.0014 & 0.0140 & 0.0071 & 0.0034 & 0.0005 \\
\hline w8 & 0.0056 & 0.0015 & 0.0164 & 0.0228 & 0.0005 \\
\hline w9 & 0.0090 & 0.0006 & 0.0439 & 0.0126 & 0.0005 \\
\hline w10 & 0.0063 & 0.0046 & 0.0029 & 0.0194 & 0.0005 \\
\hline w11 & 0.0056 & 0.0140 & 0.0077 & 0.0272 & 0.0005 \\
\hline w12 & 0.0912 & 0.0006 & 0.0352 & 0.0352 & 0.0005 \\
\hline w13 & 0.0101 & 0.0102 & 0.0079 & 0.0177 & 0.0005 \\
\hline w14 & 0.0024 & 0.0108 & 0.0059 & 0.0049 & 0.0009 \\
\hline w15 & 0.0059 & 0.0012 & 0.0208 & 0.0056 & 0.0016 \\
\hline w16 & 0.0028 & 0.0052 & 0.0051 & 0.0051 & 0.0005 \\
\hline
\end{tabular}

compared. Then, using Eq. (8), the corresponding weighted normalized matrix is constructed, as shown in Table 6.

Then, the sums of weighted normalized values are calculated using Eq. (9), for both maximizing parameters $\left(\mathrm{S}_{+\mathrm{i}}\right)$ and minimizing parameters $\left(\mathrm{S}_{-\mathrm{i}}\right)$. Subsequently, relative significance (priority) of each GW well was obtained by using Eq. (10). Finally, by using Eq. (11), quantitative utility for each alternative was calculated upon which the final ranking was obtained (Table 7).

Table 7. Sum of the weighted normalized values, relative significance, utility values and ranking of the groundwater wells

\begin{tabular}{|c|c|c|c|c|c|}
\hline $\begin{array}{c}\text { W. } \\
\text { NO. }\end{array}$ & $S_{+i}$ & $S_{-i}$ & $Q_{i}$ & $U_{i}$ & Rank \\
\hline w1 & 0 & 0.0711 & 0.038473 & 26.39825 & 14 \\
\hline w2 & 0 & 0.1627 & 0.016809 & 11.53313 & 15 \\
\hline w3 & 0 & 0.0667 & 0.040994 & 28.12821 & 13 \\
\hline w4 & 0 & 0.0524 & 0.052216 & 35.82801 & 9 \\
\hline w5 & 0 & 0.1944 & 0.014072 & 9.655704 & 16 \\
\hline w6 & 0 & 0.0549 & 0.049815 & 34.18062 & 11 \\
\hline w7 & 0 & 0.0249 & 0.10969 & 75.26369 & 2 \\
\hline w8 & 0 & 0.0337 & 0.081076 & 55.6299 & 4 \\
\hline w9 & 0 & 0.0464 & 0.058984 & 40.47148 & 6 \\
\hline w10 & 0 & 0.0263 & 0.104124 & 71.44464 & 3 \\
\hline w11 & 0 & 0.0467 & 0.058518 & 40.15208 & 8 \\
\hline w12 & 0 & 0.0666 & 0.041038 & 28.15829 & 12 \\
\hline w13 & 0 & 0.0351 & 0.077815 & 53.39239 & 5 \\
\hline w14 & 0 & 0.0466 & 0.058646 & 40.2399 & 7 \\
\hline w15 & 0 & 0.0526 & 0.051989 & 35.67238 & 10 \\
\hline w16 & 0 & 0.0188 & 0.145741 & 100 & 1 \\
\hline
\end{tabular}




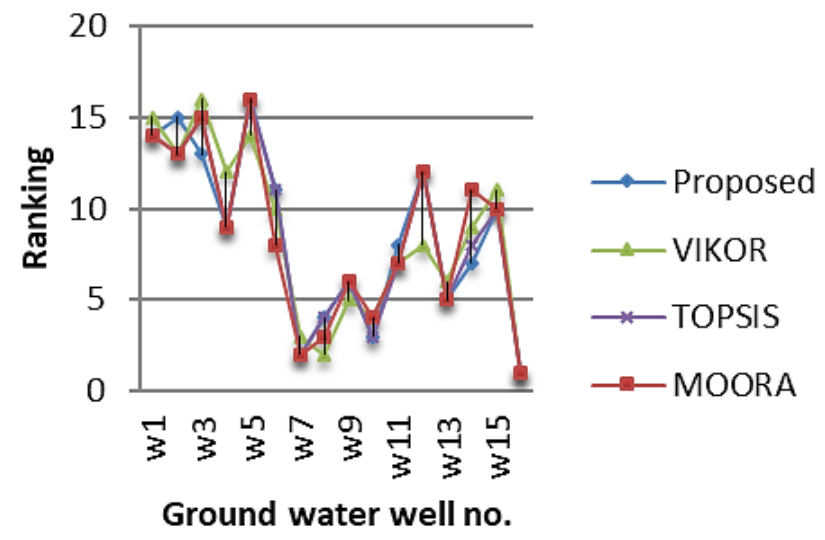

Figure. 2 Comparative rankings of suggested method with other MCDM techniques

\subsection{Comparison between the proposed method and comprehensive evaluation techniques}

To evaluate the validity and strength of the suggested methodology, the ranking results were also compared with the previously investigated optimization approaches such as: MOORA [6], VIKOR [5] and TOPSIS [4]. The results of rankings of various approaches are presented in the Fig. 2.

The results do not show much difference between the proposed method and the other MCDM methods except in the rankings of the middle rated alternatives. It can be observed that $\mathrm{GW}$ well 16 received the highest attention by all methods, hence may be regarded as the most appropriate. The results indicate that the suggested approach is consistent with the other techniques. The suggested approach is not only improve decision-making process in selecting the best alternative but also in dealing with datasets with a large number of input variables, FEA can obviously minimize the parameters of input space and calculation difficulty. A considerable amount of time is saved at the same time.

\section{Conclusions}

The assessment of GW quality is one of the key issues in water resources management. In this research, a methodology based on FEA combined with COPRAS Method and SD for GW assessment is introduced. Twelve parameter including hydrogen ion concentration $(\mathrm{pH})$, total dissolved solids (TDS), total hardness (TH), Turbidity (Turb), sulfates (SO4), chlorides $(\mathrm{Cl})$, nitrate $(\mathrm{NO} 3)$, Fluorides $(\mathrm{F})$, sodium $(\mathrm{Na})$, Zinc $(\mathrm{Zn})$ ), iron $(\mathrm{Fe})$, and Escherichia coli (E. coli) were investigated to evaluate GW quality. First, FEA was used to perform attribute reduction of parameters for water assessment. Then, the parameter weights were computed using SD. Finally, COPRAS for evaluating GW quality rankings was successfully employed. The results reveal that sulfates (SO4), nitrate (NO3), Fluorides (F), sodium (Na), and Escherichia coli (E. coli) are the main parameters for GW quality assessment. Furthermore, the optimal concentrations of physicochemical parameters: (SO4), (NO3), (F), (Na), and (E. coli) are 18.9(mg/L), 8.18(mg/L), $\quad 0.222(\mathrm{mg} / \mathrm{L}), \quad 21(\mathrm{mg} / \mathrm{L})$, 1.9(MPN/100mL), respectively. To validate the suggested approach output, three MCDM analytical techniques, including MOORA, VIKOR, and TOPSIS, are being compared. It demonstrates that the computed values for the proposed model are close to the methods MOORA, VIKOR, and TOPSIS. Hence, the suggested model is considered to be an effective evaluation method for ranking groundwater wells. We can, therefore, conclude that FEA combined with COPRAS Method and SD approach is powerful in the optimization of $\mathrm{GW}$ parameters. Moreover, the proposed approach provides a generic method that can be extended to various selection difficulties that include complexity and a variety of performance indicators. Compared to other MCDM methods, the results derived from the proposed model are reasonable and reliable to implement.

\section{Conflicts of Interest}

The author declare no conflict of interest.

\section{References}

[1] P. Piroozfar, S. Alipour, S. Modabberi, and D. Cohen, "Hydrogeochemical investigation and water quality assessment in the Sarough watershed, Takab mining district", Geosciences, Vol. 106, pp. 13-28, 2018.

[2] T. Subramani, S. Krishnan, and P. K. Kumaresan, "Study of groundwater quality with GIS application for Coonoor Taluk in Nilgiri district", International Journal of Modern Engineering Research, Vol. 2, No. 3, pp. 586-592, 2012.

[3] A. D. Gorgij, O. Kisi, A. A. Moghaddam, and A. Taghipour, "Groundwater quality ranking for drinking purposes, using the entropy method and the spatial autocorrelation index", Environmental Earth Sciences, Vol. 76, No. 7, pp. 269-277, 2017.

[4] F. Lei, G. Wei, H. Gao, J. Wu, and C. Wei, "TOPSIS Method for Developing Supplier Selection with Probabilistic Linguistic Information", International Journal of Fuzzy Systems, Vol. 22, pp. 749-759, 2020.

[5] Y. Suh, Y. Park, and D. Kang, "Evaluating mobile services using integrated weighting approach and fuzzy VIKOR", PLoS ONE, Vol. 14, No. 6, pp. 1-28, 2019. 
[6] S. K. Shihaba, N. Z. Khanb, P. Mylac, S. Upadhyayd, Z. A. Khanb and A. N. Siddiqueeb, "Application of MOORA method for multi optimization of GMAW process parameters in stainless steel cladding", Management Science Letters, Vol. 8, pp. 241-246, 2018.

[7] S. M. Shaban and A. M. AbdEl-latif, "Integration of Evaluation Distance from Average Solution Approach with Information Entropy Weight for Diesel Engine Parameter Optimization", International Journal of Intelligent Engineering and Systems, Vol. 13, No. 3, pp. 101 - 111, 2020.

[8] M. A. Baghapou and M. R. Shooshtarian, "Extending a Consensus-Based Fuzzy Ordered Weighting Average (FOWA) Model in New Water Quality Indices", Iranian Journal of Health, Safety \& Environment, Vol. 4, No. 4, pp. 824-834, 2017.

[9] Y. J. He, D. Wang, and G. L. Wang, "Fuzzy Comprehensive Evaluation on North-China Groundwater Quality", Advanced Materials Research, Vol. 610-613, pp. 2729-2733, 2012.

[10] A. D. Gorgij, J. Wu and A. A. Moghadam, "Groundwater quality ranking using the improved entropy TOPSIS method: a case study in Azarshahr plain aquifer, east Azerbaijan, Iran", Human and Ecological Risk Assessment: An International Journal, Vol. 25, No. 1-2, pp. 176-190, 2019.

[11] H. Haider, A. Ghumman, I. S. Al-Salamah, and H. Thabit, "Assessment Framework for Natural Groundwater Contamination in Arid Regions: Development of Indices and Wells Ranking System Using Fuzzy VIKOR Method", Water, Vol. 12, No. 2, pp. 423-447, 2020.

[12] A. Organ and E. Yalçın, "Performance Evaluation of Research Assistants By Copras Method", European Scientific Journal, Vol. 12, pp. 102-109, 2016.

[13] L. I. Peiyue, W. U. Jianhua, and Q. Hui, "Groundwater quality assessment based on entropy weighted osculating value method", International Journal of Environmental Sciences, Vol. 1, No. 4, pp. 621-630, 2010.

[14] Z. W. Li, Y. Fang, G. Zeng, J. B. Li, Q. Zhang, Q. S. Yuan, Y. M. Wang, and F. Y. Ye, "Temporal and spatial characteristics of surface water quality by an improved universal pollution index in red soil hilly region of South China: A case study in Liuyanghe River watershed", Environmental Geology, Vol. 58, pp. 101-107, 2009.

[15] S. S. Mahapatra, M. Sahu, R. K. Patel and B. N. Panda, "Prediction of Water Quality Using
Principal Component Analysis", Water Quality Exposure and Health, Vol. 4, pp. 93-104, 2012.

[16] V. K. Jena and D. Sinha, "Ground water quality assessment by multivariate factor analysis", Research Journal of Chemistry and Environment, Vol. 21, pp. 21-25, 2017.

[17] G. Borowik, J. Jankowski, and K. Kowalski, "Fast algorithm for feature extraction", In: Proc. of SPIE 9662, Photonics Applications in Astronomy, Communications, Industry, and High-Energy Physics Experiments 2015, Wilga, Poland, pp. 9662 3T, 2015.

[18] E. K. Zavadskas, A. Kaklauskas, Z. Turskis, and J. Tamošaitien, "Selection of the Effective Dwelling HouseWalls by Applying AttributesValues Determined at Intervals", Journal of Civil Engineering \& Management, Vol. 14, No. 2, pp. 85-93, 2008.

[19] P. Chatterjee, V. M. Athawale, and S. Chakraborty, "Materials selection using complex proportional assessment and evaluation of mixed data methods", Materials and Design, Vol. 32, No. 2, pp. 851-860, 2011.

[20] L. Uzsilaityte and V. Martinaitis, "Search for optimal solution of public building renovation in terms of life cycle", Journal of Environment Engineering and Landscape Management, Vol. 18, No. 2, pp. 102-110, 2010.

[21] L. Tupenaite, E. K. Zavadskas, A. Kaklauskas, Z. Turskis, and M. Seniut, "Multiple criteria assessment of alternatives for built and human environment renovation", Journal of Civil Engineering and Management, Vol. 16, No. 2, pp. 257-266, 2010.

[22] E. K. Zavadskas, A. Kaklauskas, F. Peldschus, and Z. Turskis, "Multi-Attribute Assessment of Road Design Solutions by Using the COPRAS Method", Baltic Journal of Road and Bridge Engineering, Vol. 2, No. 4, pp. 195-203, 2008.

[23] P. Chatterjee and S. Chakraborty, "Gear Material Selection using Complex Proportional Assessment and Additive Ratio Assessmentbased Approaches: A Comparative Study", International Journal of Materials Science and Engineering, Vol. 1, No. 2, pp. 104-111, 2013.

[24] M. N. Ibrahim, “Assessing Groundwater Quality for Drinking Purpose in Jordan: Application of Water Quality Index", Journal of Ecological Engineering, Vol. 20, No. 3, pp. 101-111, 2019. 